\title{
AN ANTICORROSION COATING FROM BALL-MILLED WOOD CHARCOAL AND TITANIUM DIOXIDE USING A FLAME SPRAY METHOD
}

\author{
Teguh Endah Saraswati ${ }^{1 *}$, Kartiko Nugroho $^{1}$, Miftahul Anwar $^{2}$ \\ ${ }^{1}$ Department of Chemistry, Faculty of Mathematics and Natural Sciences, Sebelas Maret University, \\ Jl. Ir. Sutami 36A Surakarta, 57126, Indonesia \\ ${ }^{2}$ Department of Electrical Engineering, Faculty of Engineering, Sebelas Maret University, Jl. Ir. \\ Sutami 36A Surakarta, 57126, Indonesia
}

(Received: January 2018 / Revised: April 2018 / Accepted: July 2018)

\begin{abstract}
In coating technology, many coating methods have been developed to enhance metal's resistance to corrosion. This study demonstrated the use of a simple, easy, and economical manual thermal flame spray method to create an anticorrosion coating layer composed of ballmilled wood charcoal (a readily-available source of carbon) and titanium dioxide $\left(\mathrm{TiO}_{2}\right)$. The coating materials were sprayed and melted by passing them through a flame; they were then deposited onto the surface of metal substrate of structural steel (SS) 400. We observed that the surface layers of the substrate sprayed with the wood charcoal- $\mathrm{TiO}_{2}$ mixture contained deposits such as titanium carbide, as a result of the carbothermal reduction reaction between $\mathrm{TiO}_{2}$ and the carbon present in the wood charcoal, and other iron carbide and titanium-iron oxide compounds. This deposit layer may explain why this substrate also exhibited a microhardness of more than twice that of the uncoated substrate. The coated substrate shows a darker shade than the uncoated substrate. The observation under optical microscopes shows that the uncoated metal substrate has a rougher surface with many more voids than the coated substrate. The coated surface has a water contact angle of $\sim 107^{\circ}$ indicating that a hydrophobic surface can be maintained. The coated substrates also demonstrated greater corrosion resistance to both acid and water, with the wood charcoal- $\mathrm{TiO}_{2}$-coated substrate demonstrating the best performance; in fact, its corrosion rate was nearly three times slower than that of the uncoated substrate.
\end{abstract}

Keywords: Ball milling; Charcoal; Coating; Flame thermal spray; Titanium dioxide

\section{INTRODUCTION}

Most equipment made from iron-based materials has one major weakness: susceptibility to oxidation while in contact with free air. The oxidation process corrodes iron-based metals, thereby reducing equipment lifetime and increasing metal waste, which can in turn lead to ecological degradation, especially in agricultural areas and near water sources.

Many methods have therefore been developed to coat metal substrates with anticorrosion materials. There are two approaches: wet- and dry-coating methods. These terms refer to the medium in which the deposited material is processed. Wet-coating methods mainly involve electroplating (Lowenheim \& Senderoff, 1964), electroless plating (Mallory \& Hajdu, 1990), hot-dip galvanizing (Rahrig, 1995), and corrosion-inhibitor addition (Shetty \& Shetty, 2017); dry-coating methods include, among others, vapor deposition (Pierson, 1999), thermal spray

\footnotetext{
*Corresponding author's email: teguh@mipa.uns.ac.id, Tel: +62-271-663375, Fax: +62-271-663375 Permalink/DOI: https://doi.org/10.14716/ijtech.v9i5.1266
} 
techniques (Davis, 2004; Pawlowski, 2008), brazing (Schwartz, 2003; Shapiro \& Rabinkin, 2003), weld overlays (Hattori \& Mikami, 2009), and peening and nitriding (Ariati et al., 2016).

Thermal spraying is an industrial coating process that consists of using a heat source and a coating material in a powder or wire form that is melted into tiny droplets and sprayed onto surfaces at high velocities. High-velocity oxygen fuel (HVOF) is a type of thermal spraying method which is appropriate for coating rocket nozzles for WC-Co deposition, and which provides high hardness and low porosity (Sofyan et al., 2010). However, HVOF equipment is expensive because the spray gun usually cannot be operated manually; automated manipulation is typically needed to access restricted surfaces on a complex structure due to the inflexibility of the gun. Therefore, alternative thermal spraying methods are needed, such as flame spraying. In this method, the heat is supplied from the combustion of fuel gas and oxygen; the resultant heat melts the powder or wire of the coating material. The melted material is then propelled onto the substrate at a rate that achieves high deposition quality. This method offers a cost-effective way to apply metallic and ceramic coatings in a less demanding environment. In addition, it allows for the use of a wide variety of metallic or ceramic coatings onto a broad range of component materials where excellent wear and impact resistance are required (Fauchais et al., 2010; Fauchais et al., 2011; Fauchais et al., 2014).

In addition to the coating method, it is also important to take into account the coating material. The oxidation process can be prevented through the use of anticorrosive coating materials which have sufficient hardness to prevent surface contact with the air-for example, carbides. Carbide layers can be produced using carbon-based material, and a wide variety have been successfully applied as coatings to metal substrates, including titanium carbide (TiC), which has high hardness, high chemical stability, and good electrical conductivity (Benoit et al., 2005; Li et al., 2008; Rahaei et al., 2012). TiC can be synthesized using carbothermal reduction (Sen et al., 2010), thermal plasma (Mohapatra et al., 2013), solid-state electrochemical (Osarinmwian et al., 2015), or high-energy mechanical alloying (Saba et al., 2016). In the flame spraying method, TiC is generally used as a powder feed together with other materials, such as ceramics made of simple oxides (e.g., $\mathrm{Al}_{2} \mathrm{O}_{3}$ or $\mathrm{Cr}_{2} \mathrm{O}_{3}$ ) or complex oxides (e.g., $\mathrm{MgZrO}_{3}$ ), nitrides (e.g., $\mathrm{BN}$ ), borides (e.g., $\mathrm{ZrB}_{2}$ ), or halides (e.g., CaF) (Pawlowski, 2008).

TiC can be produced during the carbothermal reduction process from the reaction between titanium dioxide $\left(\mathrm{TiO}_{2}\right)$ and carbonaceous materials at high temperatures (Swift \& Koc, 1999); however, the production of carbonaceous-based materials using conventional equipment and methods is not economically viable for application on a broad industrial scale. Our study therefore sought to use a starting material, such as carbon precursors, which could lower production costs. One potential carbon precursor material is wood charcoal, which is less expensive and readily available due to its widespread uses as a liquid ink, a coal source, a raw material for pencils, and a water purification adsorbent (Ishimaru et al., 2007).

We therefore posited that wood charcoal could be used as the raw material for the production of carbide via carbothermal reduction reactions with metal oxides, e.g., $\mathrm{TiO}_{2}$, for use in creating an anticorrosive coating for iron-based metals. Carbothermal reactions can be achieved in either liquid (Zhong et al., 2011) or powdery solid (Sen et al., 2010; Rahaei et al., 2012) states. Although liquid is generally used to achieve homogeneous carbon-based suspensions or solutions, liquids and suspensions should be avoided during the carbothermal process for safety reasons due to the flammable nature of the organic solvent.

Therefore, to achieve a successful carbothermal reaction between wood charcoal and $\mathrm{TiO}_{2}$, mechanical processing is required for optimal results. Ball milling is a relatively inexpensive and effective powdery solid-phase mechanical processing method which provides not only a reduced-size material (Ohara et al., 2011), but also a homogeneous powder mixture even in its 
atomic and crystallographic phases (Fecht, 1995). After ball milling, the carbon from the wood charcoal will react effectively with the $\mathrm{TiO}_{2}$ to form carbides when treated with heat, for example by using the flame thermal method.

In the present study, we describe a modified manual flame thermal spraying method that uses a simple, operator-friendly design with low-cost initial materials of $\mathrm{TiO}_{2}$ and carbon present in the wood charcoal which supposedly reacted to produce titanium carbide coating layers. Overall, our results indicated that this method successfully deposited coating layers onto metal substrates.

An examination of the physical and chemical characteristics of the substrates treated with coating layers composed of wood charcoal with and without the addition of $\mathrm{TiO}_{2}$ indicated that the addition of $\mathrm{TiO}_{2}$ enhanced corrosion resistance, although wood charcoal alone was also an improvement over no treatment at all. Ultimately, we conclude that the TiC deposits produced with the wood charcoal- $\mathrm{TiO}_{2}$ coating using our proposed flame spraying method helped to protect metal substrates against corrosion, and we suggest that this method is feasible for future applications in home industries that produce metal-based products.

\section{EXPERIMENTAL METHODS}

\subsection{Materials and Equipment}

Wood charcoal (commercial charcoal of non-teak wood) and technical-grade $\mathrm{TiO}_{2}$ were supplied by Bratachem (Indonesia) and were used as starting materials. Hydrogen chloride ( $\mathrm{HCl}) 3 \mathrm{M}$ (Merck) was used to test corrosion resistance against acid. Compressed air and butane gases (HI-COOK, Indonesia) were used as combustion gases in the thermal spray coating application. A planetary ball miller (FT UNS) with constant speed was used to prepare the mixture of initial materials. A gas torch butane burner automatic flame gun (Vitatools) was modified for use in the flame spraying process. X-ray diffraction (XRD) (Shimadzu LabX XRD-6000) was used to characterize the crystallinity of the starting materials and coated substrates.

\subsection{Procedures}

\subsubsection{Preparation of the powder spray materials using ball milling}

The first step in our experiment was to establish a ball milling process that optimized the size reduction of the wood charcoal. We tested the process using a constant speed of $1200 \mathrm{r} / \mathrm{min}$ for $1,3,5$, and 7 hours. To assess the results, the mixtures were then filtered by 200 mesh, and the particle yields after meshing were compared. The mixture of wood charcoal and $\mathrm{TiO}_{2} \mathrm{was}$ prepared using a ratio of $2: 5(\mathrm{w} / \mathrm{w})$, respectively. This ratio was determined using the stoichiometry reaction of the carbothermal reduction of carbon and $\mathrm{TiO}_{2}$ to produce $\mathrm{TiC}$ (Swift $\&$ Koc, 1999). Both samples were ball-milled according to the optimal milling time obtained previously. The milled particles were then collected for use as the powder feed for the coating material.

\subsubsection{The coating process using the powder flame thermal spraying method}

The coatings were applied to the metal substrate of a structural carbon steel SS 400 (JIS G3101) plate measuring $50 \times 50 \times 1.5 \mathrm{~mm}$. The metal substrate was first treated with abrasive paper and rinsed with distilled water, alcohol, and acetone.

The flame thermal spray equipment used was an operator-friendly design that was connected to a powder feed and a gas carrier line, as shown in Figure 1. The flame gun was modified from a commercial flame gun (Vitatools) by connecting the chamber of the powder feed and the gas line to the air compressor. Spraying was maintained by adjusting the flow rates of the butane gas and compressed air from the compressor, using an air flow of $\sim 20 \mathrm{~L} / \mathrm{min}$, until the coating 
material could be consistently sprayed and deposited onto the metal substrate. After spraying, the treated metal substrates were then analyzed and characterized.
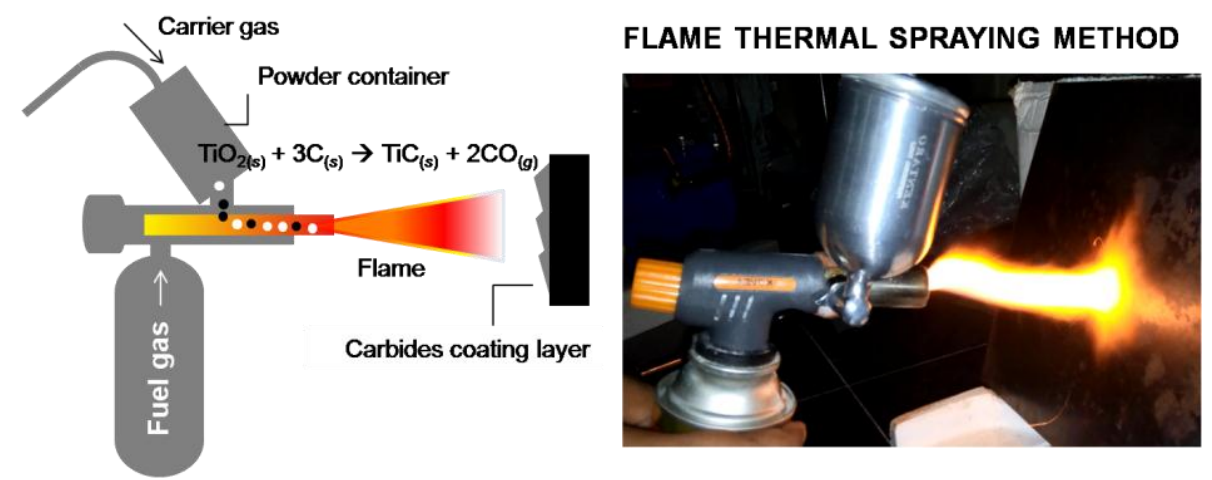

Figure 1 The operator-friendly modified spray gun used in our flame thermal spraying method

\subsubsection{Characterization}

The crystal structure characteristics of the coated samples were analyzed using XRD and the relevant crystallography database of Joint Committee on Powder Diffraction Standards (JCPDS). Contact angle, corrosion resistance, and microhardness tests were also used to characterize its hydrophobicity, corrosion, and hardness, respectively. The contact angle test was performed by placing a drop of water onto the substrate surface and measuring the angle between the water droplet and the substrate surface; the contact angle was then estimated from the angle where the water droplet interface met a solid surface and was measured using the free software OnScreenProtactor (version 0.5). The corrosion resistance test was performed by spraying $3 \mathrm{M} \mathrm{HCl}$ over the surfaces of the substrates. The substrates were left sprayed-surfaceup for 5 hours in the open air, and the corrosion rate was subsequently calculated using the following equation:

$$
m p y=\frac{534 \times W}{D \times A \times T}
$$

where mpy represents the corrosion rate in miles per year and $W, D, A$ and $T$ represent weight loss $(\mathrm{mg})$, density $\left(\mathrm{g} / \mathrm{cm}^{3}\right)$, surface area $\left(\mathrm{in}^{2}\right)$, and test time (hours), respectively (Samal et al., 2011).

Microhardness was assessed using the Vickers hardness test (Buehler) with a constant load of $100 \mathrm{mgf}$. The microhardness values were then calculated using the following equation:

$$
\mathrm{H}_{\mathrm{V}}=1.8544 \times \frac{\mathrm{P}}{\mathrm{d}^{2}}
$$

where $H_{V}$ is the Vickers Hardness Number (VHN) in $\mathrm{kgf} / \mathrm{mm}^{2}$. The number is multiplied by 9.807 to convert to MPa. $P$ is the standard load in $\mathrm{kg}$, and $d$ is the average diagonal in $\mathrm{mm}$ (Donald \& McCurrie, 1972; Lawn \& Marshall, 1979).

\section{RESULTS AND DISCUSSION}

\subsection{Preparation of the Powder Spray Materials using Ball Milling}

We prepared the powder coating materials using the ball milling method, which reduces or minimizes the size of the initial material using steel ball collisions with the material via to the rotation and revolution of a gear attached to an electric motor (Ohara et al., 2011). There are 
three stages in the ball milling method: the grinding stage, which increases the atomic strain; the small grain formation stage, in which mechanical attrition occurs; and the atomic and crystallographic phase stage, in which the final granules are formed (Fecht, 1995).

Therefore, the powder coating materials were milled not only to reduce particle size (i.e., increase each particle's surface area), but also to ultimately achieve successful carbide formation during thermal spraying by providing more sites for carbothermal reactions to occur. The resulting ball-milled wood charcoal particles are presented in Table 1.

Table 1 Yields of the wood charcoal ball-milled particles

\begin{tabular}{ccccccc}
\hline No. & $\begin{array}{c}\text { Time } \\
\text { (hours) }\end{array}$ & $\begin{array}{c}\text { Rotation } \\
\text { Frequency } \\
(\mathrm{r} / \mathrm{min})\end{array}$ & $\begin{array}{c}\text { Initial } \\
\text { Weight }(\mathrm{g})\end{array}$ & $\begin{array}{c}\text { Passing } \\
\text { particles } \\
\text { through mesh } \\
200(\mathrm{~g})\end{array}$ & $\begin{array}{c}\text { Non passing } \\
\text { particles } \\
\text { through mesh } \\
200(\mathrm{~g})\end{array}$ & $\begin{array}{c}\text { Yield } \\
(\%)\end{array}$ \\
\hline 1. & 1 & 1200 & 20 & 10.22 & 8.77 & 51.11 \\
2. & 3 & 1200 & 20 & 13.58 & 5.33 & 67.90 \\
3. & 5 & 1200 & 20 & 15.49 & 3.15 & 77.43 \\
4. & 7 & 1200 & 20 & 15.69 & 2.56 & 78.44 \\
\hline
\end{tabular}

As shown in Table 1, a milling time of 7 hours yielded the highest amount of material that was able to penetrate through the mesh, most likely suggesting the production of more microsized particles during the longer ball milling process. In other words, the higher particle yield indicated a higher probability of microsized material being obtained. However, the yield difference decreased over time due to the material becoming saturated, wherein the materials in the bottom chamber became motionless, hard, and tight. Moreover, the size reduction process in the bottom chamber was not optimal due to the equilibrium of the milling state phenomenon (Balaz et al., 2013), wherein particles reached a minimum size but then merged into a new, larger size, thereby reducing the efficiency of the milling process.

Thus, for the sake of time efficiency, we found that 5 hours of milling was ideal because it provided a lower difference yield $( \pm 1 \%)$ than that produced by milling for 7 hours. Overall, based on the milling results that are presented in Table 1, we chose to apply a 5-hour milling time at $1200 \mathrm{r} / \mathrm{min}$ to prepare the powder coating material. The milled materials were then used as a feed in the coating process.

\subsection{The Coating Process using a Powder Flame Thermal Spraying Method}

Our flame thermal spraying method was conducted using butane and compressed air, which we used not only as a gas carrier of the powder material but also as a fuel gas. The heat was supplied from combustion using the mixed gases; it melted the powder coating material and simultaneously provided the necessary conditions for the occurrence of the carbothermal reduction reaction.

XRD was used to analyze the changes before and after spraying. The XRD spectra shown in Figure 2 depict a substrate coated with the wood charcoal- $\mathrm{TiO}_{2}$ mixture (Figure 2A) and a substrate coated with wood charcoal alone (Figure 2B). Although they show similar patterns, three characteristic low-intensity peaks appeared at $2 \theta$ around $35^{\circ}(111), 40^{\circ}(200)$, and $57^{\circ}$ (220) (JCPDS 74-1219) that corresponded to the formation of TiC after applying the spray to the substrate. This compound was formed by carbothermal reduction during the coating process according to the following chemical reaction:

$$
\mathrm{TiO}_{2(s)}+3 \mathrm{C}_{(\mathrm{s})} \rightarrow \mathrm{TiC}_{(\mathrm{s})}+2 \mathrm{CO}_{(\mathrm{g})}
$$


As shown in Figure 2, other carbide compounds were also observed, such as $\mathrm{Fe}_{2} \mathrm{C}$ (110) (JCPDS 37-0999), $\mathrm{Fe}_{3} \mathrm{C}$ (211), (102), and (031) (JCPDS 85-1317), $\mathrm{Fe}_{5} \mathrm{C}_{2}$ (402) (JCPDS 200508), and $\mathrm{Fe}_{7} \mathrm{C}_{3}$ (220) (JCPDS 17-0333). Moreover, iron oxide compounds such as $\mathrm{FeTiO}_{3}$ (104) (JCPDS 79-1838) and $\mathrm{Fe}_{3} \mathrm{O}_{4}$ (220), (311), and (440) (JCPDS 77-1545) were also present. The carbon peak at $2 \theta$ around $27^{\circ}(002)$ (JCPDS 41-1487) appeared in the raw material but had already disappeared after spraying, indicating that the reacted carbon became carbide and that the others burned as carbon monoxide gases, as shown in reaction (3).

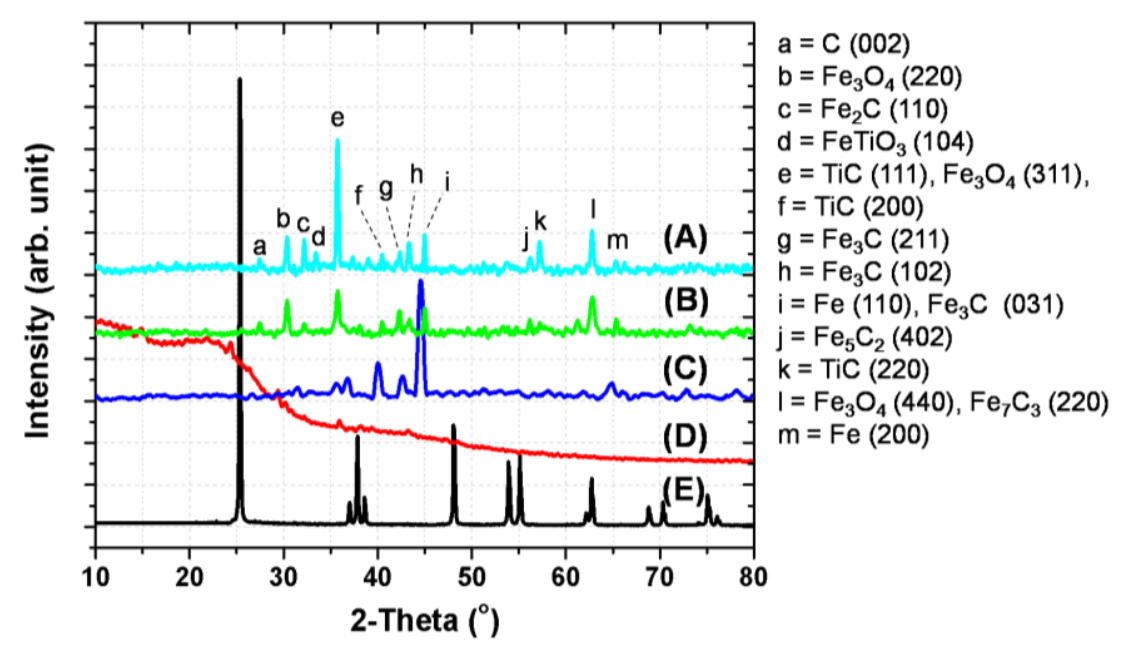

Figure 2 The XRD spectra of: (A) the metal substrate coated with wood charcoal- $\mathrm{TiO}_{2}$; (B) the metal substrate coated with wood charcoal alone; (C) the uncoated metal substrate; (D) the wood charcoal coating material; and (E) the $\mathrm{TiO}_{2}$ coating material

The flame thermal spray coating results are presented in Figure 3. There was a significant difference in substrate appearance before and after the coating treatments. The substrates coated with both the wood charcoal alone and the wood charcoal- $\mathrm{TiO}_{2}$ mixture had a visibly rough surface with a darker appearance, as shown in Figures $3 \mathrm{~B}$ and $3 \mathrm{D}$, respectively. The temperature of the surface of the metal substrate while the coating was being sprayed was over $500^{\circ} \mathrm{C}$ as measured by an infrared thermometer-easily sufficient to deposit the material onto the metal surface.

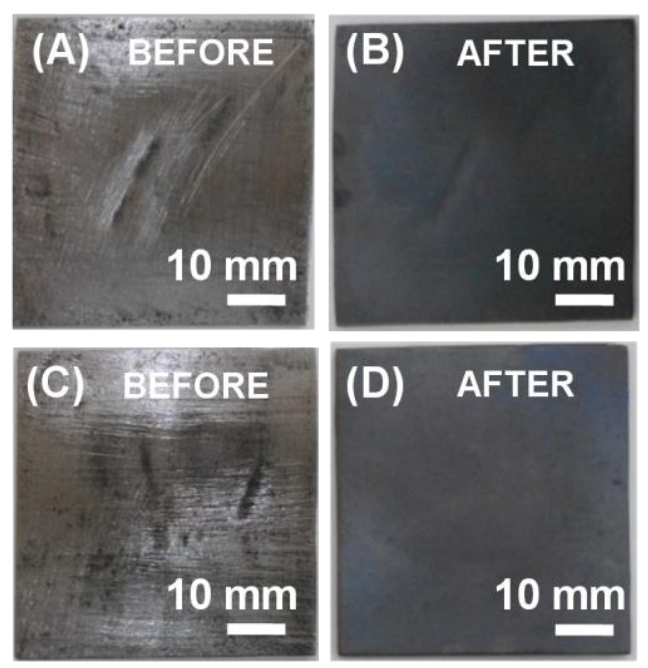

Figure 3 The surface appearance of: (A) the uncoated metal substrate before coated by charcoal; (B) the metal substrate coated with charcoal; (C) the uncoated metal substrate before coated by charcoal and $\mathrm{TiO} 2$; and (D) the metal substrate coated with a mixture of charcoal and $\mathrm{TiO} 2$ 
Figure 4 provides greater detail of the morphological surfaces by showing the substrate before and after coating using $100 \times$ magnification. After the coating materials were sprayed onto the metal substrates, most of the shallow fibrous slots (Figure 4A) were filled with coating material, resulting in an un-shallow, smoother surface (Figures $4 \mathrm{~B}$ and $4 \mathrm{C}$ ). The wood charcoal- $\mathrm{TiO}_{2}$ mixture gave better results than the wood charcoal alone; it had a better deposition quality due to the reduced size of the coating particles that were produced from the ball milling process, and was thus better able to fill the fibrous slots of the metal substrate.
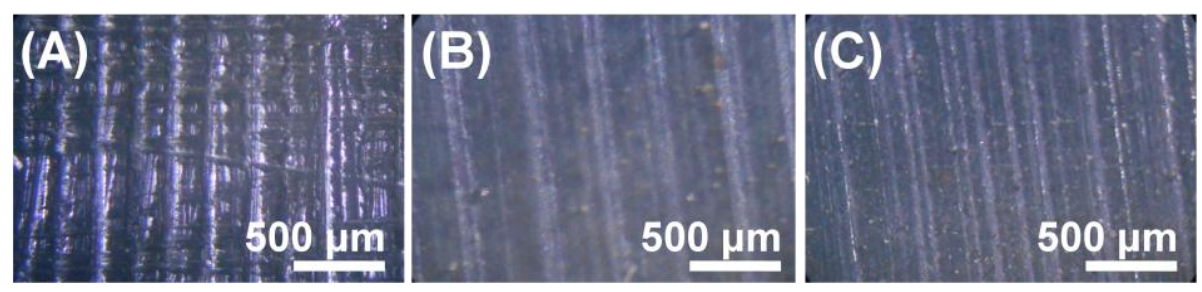

Figure 4 The morphological surfaces of: (A) the uncoated metal substrate; (B) the metal substrate coated with wood charcoal alone; and $(\mathrm{C})$ the metal substrate coated with the mixture of wood charcoal and

$\mathrm{TiO}_{2}$. All photographs were taken with an optical microscope

Figure 5 shows water droplet contact angles corresponding to material wettability. The wood charcoal- $\mathrm{TiO}_{2}$ coating provided the greatest contact angle, indicating that the substrate coated with wood charcoal- $\mathrm{TiO}_{2}$ surface was more hydrophobic than that coated with wood charcoal alone. Higher hydrophobicity means that there is less contact between the substrate surfaces and the water droplets that would initiate metal corrosion. Other research has also found that adding $\mathrm{TiO}_{2}$ to metal coatings increased the water-surface contact angle and thus improved the substrate's hydrophobicity (La Russa et al., 2016).
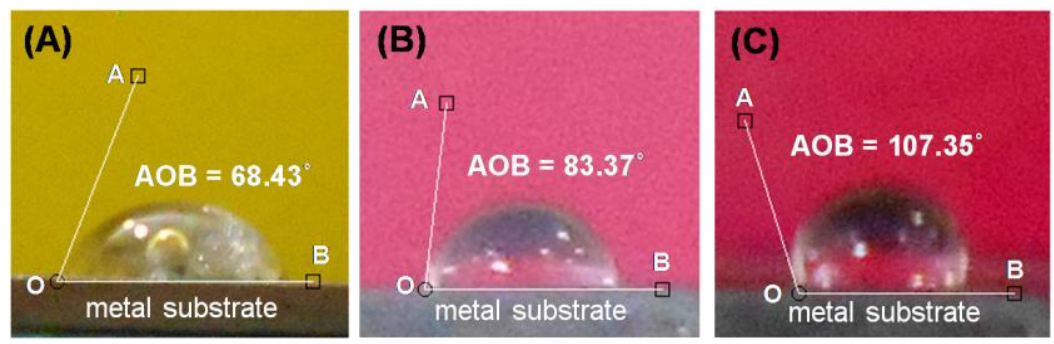

Figure 5 The profiles of water drop contact angle on the surface of: (A) the uncoated metal substrate; (B) the metal substrate coated with wood charcoal, and (C) the metal substrate coated with a mixture of wood charcoal and $\mathrm{TiO}_{2}$

The results of the $H_{V}$ and corrosion rate tests, which we performed in order to complement our understanding of the substrate surface characteristics after treatment, are presented in Table 2 . The VHN was calculated by measuring the diagonal lengths of an indent left by applying a diamond pyramid indenter with a given load onto the specimen material. Microhardness is related to surface erosion, particularly in extreme environmental conditions. We found that the wood charcoal- $\mathrm{TiO}_{2}$ coating resulted in a metal substrate with the highest microhardness, while the untreated metal substrate had the lowest microhardness. Similarly, corrosion resistance was significantly higher in the substrate coated with the charcoal- $\mathrm{TiO}_{2}$ mixture than in the substrate coated with wood charcoal alone, though both treatments were an improvement over the untreated substrate. 
Table 2 Microhardness and corrosion resistance before and after treatments

\begin{tabular}{clcc}
\hline No. & Sample & $H_{V}(\mathrm{MPa})$ & Corrosion rate $(\mathrm{mpy})$ \\
\hline 1. & Uncoated metal substrate & 1561.83 & 288.07 \\
2. & The coated metal substrate with wood charcoal & 2084.80 & 148.20 \\
3. & The coated metal substrate with a mixture of & 3873.73 & 111.56 \\
& & \\
\hline
\end{tabular}

Compared to the wood charcoal spraying, the wood charcoal- $\mathrm{TiO}_{2}$ mixture spraying significantly improved the microhardness and the corrosion resistance. Thus, $\mathrm{TiO}_{2}$ addition improved the physical properties of the metal substrate. The carbide presence after treatment shown in the XRD pattern (Figure 2) was responsible to the higher microhardness, leading to the lower corrosion rate (Klyatskina et al., 2015).

Figure 6 shows the substrate after it was exposed to hydrochloric acid. The treated and untreated substrates demonstrated a significant difference in their resistance to acid corrosion. For each substrate, the golden area indicates corrosion, while the darker area indicates uncorroded areas. More dark areas thus indicate greater resistance to corrosion. The metal substrate coated with the wood charcoal- $\mathrm{TiO}_{2}$ mixture performed better than the substrate coated with wood charcoal alone, confirming its lower corrosion rate as shown in Table 2.
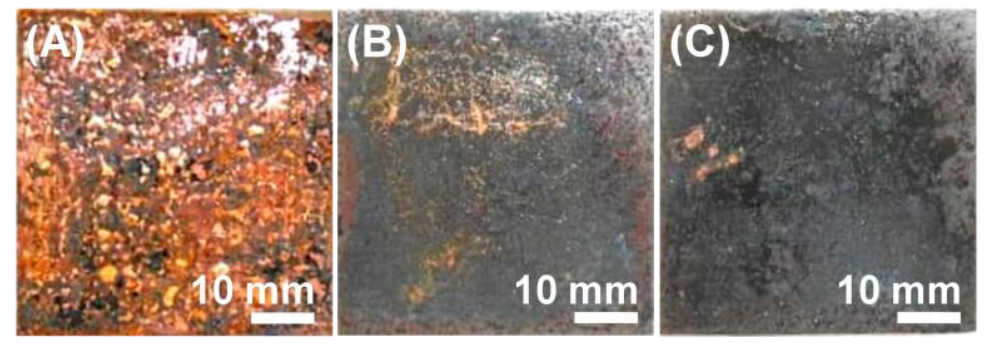

Figure 6 Performance of the metal substrate after exposed to acid: (A) Uncoated metal substrate; (B)

Metal substrate coated with wood charcoal alone; and (C) Metal substrate coated with the wood charcoal- $-\mathrm{TiO}_{2}$ mixture

Overall, the wood charcoal- $\mathrm{TiO}_{2}$ coating improved the physical properties of the metal substrate as compared to those of both the uncoated substrate and the substrate coated with wood charcoal alone. The higher microhardness of the substrate coated with wood charcoal$\mathrm{TiO}_{2}$ was likely due to the higher carbide presence after treatment with the $\mathrm{TiO}_{2}$-inclusive coating, as shown by its XRD pattern (Figure 2), which in turn would be expected to lead to a higher microhardness and a lower corrosion rate. Our results were consistent with this expectation. Moreover, the hydrophobic surface characteristic of the coating allowed for less contact between the substrate and the acid solution, thereby reducing the substrate's spontaneous corrosion.

\section{CONCLUSION}

Our results indicated that using flame spraying to coat metal substrates with a mixture of ballmilled wood charcoal and $\mathrm{TiO}_{2}$ could potentially be useful to prevent metal corrosion. Our flame spraying method successfully deposited the coating materials onto the metal surface. Overall, the addition of $\mathrm{TiO}_{2}$ improved the physical properties of the metal substrate compared to the use of wood charcoal alone or to no treatment. After spraying the substrate with the wood 
charcoal- $\mathrm{TiO}_{2}$ mixture, the surface composite layers contained deposits such as $\mathrm{TiC}$, which was a product of the carbothermal reduction reaction between $\mathrm{TiO}_{2}$ and the carbon present in the wood charcoal, and other iron carbides and titanium-iron oxides. The substrate's morphological structure also became smoother after the wood charcoal- $\mathrm{TiO}_{2}$ treatment, because the sprayed material - comprised of tiny particles as a result of the ball milling process-filled the fibrous slots of the metal substrate. The wood charcoal- $\mathrm{TiO}_{2}$ coating also gave the metal substrate a higher liquid contact angle $\left(>90^{\circ}\right)$, as well as a microhardness nearly twice that of the uncoated substrate and a corrosion rate that was nearly three times slower than that of the uncoated metal substrates. We conclude that the formation of the carbide layer deposited by the wood charcoal$\mathrm{TiO}_{2}$ treatment could account for the increased microhardness and, consequently, some of the increased resistance to corrosion.

\section{ACKNOWLEDGEMENT}

This work was partly supported by Grants-in-Aid Research from the Ministry of Research, Technology and Higher Education under project No. 339/UN27.11/PL/2015 and 474/UN27.21/PP/2018.

\section{REFERENCES}

Ariati, M., Nurjaya, D.M., Rooscote, D., 2016. The Effect of Double Shot Peening and Nitriding on the Die Soldering Behavior of H13 and Cr-Mo-V Tool Steel. International Journal of Technology, Volume 7(3), pp. 463-470

Balaz, P., Achimovicova, M., Balaz, M., Billik, P., Cherkezova-Zheleva, Z., Criado, J.M., Delogu, F., Dutkova, E., Gaffet, E., Gotor, F.J., Kumar, R., Mitov, I., Rojac, T., Senna, M., Streletskii, A., Wieczorek-Ciurowa, K., 2013. Hallmarks of Mechanochemistry: From Nanoparticles to Technology. Chemical Society Reviews, Volume 42(18), pp. 7571-7637

Davis, J.R., 2004. Handbook of Thermal Spray Technology. ASM International

Donald, I.W., Mccurrie, R.A., 1972. Microstructure and Indentation Hardness of an MgO-Li,O$\mathrm{Al}, \mathrm{O},-\mathrm{SiO},-\mathrm{TiO}$, Glass-Ceramic. Journal of the American Ceramic Society, Volume 55(6), pp. 289-291

Fecht, H.J., 1995. Nanostructure Formation by Mechanical Attrition. NanoStructured Materials, Volume 6(1-4), pp. 33-42

Hattori, S., Mikami, N., 2009. Cavitation Erosion Resistance of Satellite Alloy Weld Overlays. Wear, Volume 267(11), pp. 1954-1960

Ishimaru, K., Hata, T., Bronsveld, P., Nishizawa, T., Imamura, Y., 2007. Characterization of $\mathrm{sp}^{2}$ - and $\mathrm{sp}^{3}$-bonded Carbon in Wood Charcoal. Journal of Wood Science, Volume 53(5), pp. $442-448$

Klyatskina, E., Rayón, E., Darut, G., Salvador, M.D., Sánchez, E., Montavon, G., 2015. A Study of the Influence of $\mathrm{TiO}_{2}$ Addition in $\mathrm{Al}_{2} \mathrm{O}_{3}$ Coatings Sprayed by Suspension Plasma Spray. Surface and Coatings Technology, Volume 278, pp. 25-29

La Russa, M.F., Rovella, N., Alvarez De Buergo, M., Belfiore, C.M., Pezzino, A., Crisci, G.M., Ruffolo, S.A., 2016. Nano-TiO 2 Coatings for Cultural Heritage Protection: The Role of the Binder on Hydrophobic and Self-cleaning Efficacy. Progress in Organic Coatings, Volume 91, pp. 1-8

Lawn, B.R., Marshall, D.B., 1979. Hardness, Toughness, and Brittleness: An Indentation Analysis. Journal of the American Ceramic Society, Volume 62(7-8), pp. 347-350

Lowenheim, F.A., Senderoff, S., 1964. Modern electroplating. Journal of the Electrochemical Society, Volume 111(11), pp. 262C-263C

Mallory, G.O., Hajdu, J.B., 1990. Electroless Plating: Fundamentals and Applications. American Electroplaters and Surface Finishers Societ, New York, USA 
Mohapatra, S., Mishra, D.K., Singh, S.K., 2013. Microscopic and Spectroscopic Analyses of TiC Powder Synthesized by Thermal Plasma Technique. Powder Technology, Volume 237, pp. 41-45

Ohara, S., Tan, Z., Abe, H., 2011. Novel Mechanochemical Synthesis of Carbon Nanomaterials by a High-Speed Ball-Milling. Advanced Materials Research, Volume 284-286, pp. 755758

Osarinmwian, C., Roberts, E.P.L., Mellor, I.M., 2015. Solid State Electrochemical Synthesis of Titanium Carbide. Chemical Physics Letters, Volume 621, pp. 184-187

Pawlowski, L., 2008. The Science and Engineering of Thermal Spray Coatings. John Wiley \& Sons

Pierson, H.O., 1999. Handbook of Chemical Vapor Deposition: Principles, Technology and Applications. Noyes Publications/William Andrew Publishing, LLC

Rahaei, M.B., Yazdani Rad, R., Kazemzadeh, A., Ebadzadeh, T., 2012. Mechanochemical Synthesis of Nano TiC Powder by Mechanical Milling of Titanium and Graphite Powders. Powder Technology, Volume 217, pp. 369-376

Rahrig, P., 1995. Hot Dip Galvanizing. Modern Steel Construction, Volume 35(4), pp. 36-41

Saba, F., Kabiri, E., Khaki, J.V., Sabzevar, M.H., 2016. Fabrication of Nanocrystalline TiC Coating on AISI D2 Steel Substrate via High-Energy Mechanical Alloying of Ti and C. Powder Technology, Volume 288, pp. 76-86

Samal, S., Bhattaacharyya, A., Mitra, S.K., 2011. Study on Corrosion Behavior of Pearlitic Rail Steel. Journal of Minerals \& Materials Characterization \& Engineering, Volume 10(7), pp. 573-581

Schwartz, M.M., 2003. Brazing. ASM International

Sen, W., Sun, H., Yang, B., Xu, B., Ma, W., Liu, D., Dai, Y., 2010. Preparation of Titanium Carbide Powders by Carbothermal Reduction of Titania/Charcoal at Vacuum Condition. International Journal of Refractory Metals and Hard Materials, Volume 28(5), pp. 628632

Shapiro, A., Rabinkin, A., 2003. State of the Art of Titanium-Based Brazing Filler Metals. Welding Journal, Volume 82, pp. 36-43

Shetty, D.S., Shetty, N., 2017. Inhibition of Mild Steel Corrosion in Acid Medium. International Journal of Technology, Volume 8(5), pp. 909-919

Sofyan, B.T., Berndt, C.C., Stefano, M., Pardede, H.J., 2010. WC-Co Coatings for High Temperature Rocket Nozzle Applications: An Applications Note. International Journal of Technology, Volume 1, pp. 48-56

Swift, G.A., Koc, R., 1999. Formation Studies of TiC from Carbon Coated $\mathrm{TiO}_{2}$. Journal of Materials Science, Volume 34(13), pp. 3083-3093

Zhong, J., Liang, S., Wang, K., Wang, H., Williams, T., Huang, H., Cheng, Y.-B., 2011. Synthesis of Mesoporous Carbon-Bonded TiC/SiC Composites by Direct Carbothermal Reduction of Sol-Gel Derived Monolithic Precursor. Journal of the American Ceramic Society, Volume 94(11), pp. 4025-4031 